\title{
The Role of Cooking for Hospital Food Service in Cancer Care-Units: Nutrition Is a Supportive Care While Cooking Appears to Be a Prescription
}

\author{
Philippe R. Pouillart ${ }^{*}$, Elodie Gidoin-Dewulf1 ${ }^{1}$, Cécile Foissy ${ }^{1}$, Eva Joubert ${ }^{2}$, \\ Magali Thieulent ${ }^{2}$, Odile Compère ${ }^{3}$, Sif Bendjaballah ${ }^{3}$ \\ ${ }^{1}$ Department of Nutrition and Health Sciences, Institut Polytechnique LaSalle Beauvais, Hauts de France, France \\ ${ }^{2}$ DAVIGEL, Normandie, France \\ ${ }^{3}$ Centre Hospitalier de Beauvais, Hauts de France, France \\ Email: "philippe.pouillart@lasalle-beauvais.fr
}

Received 13 April 2016; accepted 15 May 2016; published 18 May 2016

Copyright (C) 2016 by authors and Scientific Research Publishing Inc.

This work is licensed under the Creative Commons Attribution International License (CC BY).

http://creativecommons.org/licenses/by/4.0/

(c) (†) Open Access

\begin{abstract}
Cancer cachexia and treatment-induced side effects can contribute to deterioration in nutritional status in patients declining the quality of life and survival rates. Culinary practices may provide new strategies to minimize the symptoms. NEODIA (learning to live with a cancer on a day-to-day basis) is an observational program whose objective is to better understand the occurrence of treatment-related side effects as well as culinary and dietary habits in cancer patients followed in the Cancer Unit of the Beauvais City Hospital, France. First study step in 2010 has investigated culinary solutions to improve the quality of life of the patient at home. The present part tries in particular to answer the question if the culinary advising is transposable to the offer of restoration proposed by institutions of care in oncology. We first conducted an investigation on the determinants of quality of life in patients currently treated in a hospital service involving 41 people. In a second step, we are collecting information on the food supply itself, using advising of some patient's specially prepared to test meals as a translational research expertise. The results of our survey show that patient's remarks constitute real guidelines to adapt the practices in culinary production and healthy catering management. Based on these results, the consistency of frozen prepared meals has been analyzed regarding their potential to regulate the under nutritioninducing treatment-related side effects. Conducted by the patient's panel of the translational research group the study highlights the benefits of agro-food products and margins of progress.
\end{abstract}

${ }^{*}$ Corresponding author.

How to cite this paper: Pouillart, P.R., Gidoin-Dewulf, E., Foissy, C., Joubert, E., Thieulent, M., Compère, O. and Bendjaballah, S. (2016) The Role of Cooking for Hospital Food Service in Cancer Care-Units: Nutrition Is a Supportive Care While Cooking Appears to Be a Prescription. Journal of Cancer Therapy, 7, 352-361. http://dx.doi.org/10.4236/jct.2016.75038 


\title{
Keywords
}

\author{
Oncology, Side Effects, Translational Research, Therapeutic Cuisine, Food Services, Culinary \\ Sciences
}

\section{Introduction}

A recent retrospective analysis showed that the rate of malnutrition in cancer patients is greater than $55 \%$ with $5 \%$ weight loss [1]. This is directly associated to cancer cachexia [1]. The role of nutritional counselling by dieticians is therefore essential to improve the quality of life of the patient at home and for reducing the risk of cancer cachexia, exacerbated by malnutrition due to the side effects of treatments. In addition, dieticians are also directly in touch with caregivers, so that the involvement of all actors allows optimizing the dietary compliance [2].

Cancer, as once fatal disease has become a chronic condition, because chemotherapy can today stabilize the disease advancement, even in metastatic stages [1]. As a consequence, the nutritional approach, which has been initially considered as secondary treatment has gained considerably importance, as stated Hébutern [1].

According to the individual situations, patients can experience olfacto-gustatory distortions, swallowing difficulties, dental receding, canker sores, gingivitis, a drying mouth, bowel and stomach pain, nausea, cognitive problems, constipation, or conversely a diarrhea [1] [3]. The patients need to learn to live with these symptoms which are impacting the food act. Furthermore, these side effects are source of discomfort, fatigue or pain and are directly or indirectly related to the state of malnutrition [2]-[4]. In the NEODIA program we started in 2010 (learning to live with a cancer on a day-to-day basis), we have shown that patients are excluded from their kitchen while the food act is more than ever crucial to optimize the benefit of treatments [5]. Cytotoxic chemotherapy creates an energy expenditure which is a factor of additional risk of malnutrition [6], in addition to the cachexia induced fatigue, anorexia, early satiety, and anemia. Clinicians believe that the effectiveness of chemotherapy in these patients is affected, increased toxicity and the prognosis as many aggravated [7]-[15]. This essentially iatrogenic undernutrition is questioned in $25 \%$ of deaths [6].

The observational program NEODIA is focused on the dietary and cooking behaviour of cancer patients. Going beyond the recommendations of the French Society of Clinical Nutrition and Metabolism (SFNEP), the program is the first study interested in promoting the reappropriation of the "cooking space" by the patients in their homes, considering that this is a crucial setting to prevent and reduce malnutrition.

Data were collected in 197 cancer in- or out-patients (31.6\% colorectal cancer, 27.6\% breast cancer, 7.9\% non-Hodgkinien lymphoma, 7.5\% esophageal/gastric cancer, 6.6\% liver cancer, 5\% lung cancer, and others) who were receiving treatment at the Department of Oncology of the Beauvais City Hospital, France. The validated 145-item questionnaire inquired the occurrence and frequency of treatment-induced side effects, making correlations with frequency and consumption of food and beverages as well as culinary habits [5]. We observe that $60 \%$ of the participants have reported at least one treatment-induced side effect and expressed a desire to be accompanied over the long-term caregiving along the journey. Thus, NEODIA translational research group designed a culinary education program that has been developed through workshops for patients and their families. The data-driven deployment of the culinary practices was monthly evaluated by 3 scientists and 10 female patients for perceived ease of use and acceptability of the culinary solutions. In the end, NEODIA has set up the website "Vite fait bienfaits ${ }^{\circledR \text { " }}$ which literally means "right cooking for a right life" focused for oncology. Its smartphone application is downloadable in the stores Apple and Android.

This free multi-display medium is certified by the regional agency of health (ARS Hauts de France), the French National Program of Diet (PNA) power through the initiative "eating is everybody's business", and the French league against cancer (departmental committee of Oise).

The web site allows inquiring about major side effects, promotes the use of appropriate culinary techniques, and the use of specific spices and aromatic plants as well as dietary recommendations. Internet user can ask their questions, geo-locate charities or associations promoting health. In addition, patients and caregivers can offer their own recipe suggestions to enrich the library of existing recipes that are subject to the validation by the NEODIA research group before online publication. 
Culinary education regular workshops for cancer patients were firstly implemented in the Beauvais hospital in early 2015. A standardized ongoing training dedicated for caregiver's staffs was also established to transfer this knowledge. Numerous meetings and conferences in France involving 160 hospitals to facilitate local initiatives have been held by the NEODIA experts.

Despite this success to improve the quality of life of the patient at home, the program tries in particular to answer the question if the culinary advising is transposable to the offer of restoration proposed by institutions of care in Oncology. To answer this question, we first conducted an investigation on the determinants of dietary behaviour in patients currently treated in a hospital service. In a second step, we are collecting information on the food supply itself.

To do this, we have worked in a sensory analysis laboratory with a panel of trained patients followed in the same hospital. We know that each medical institution possess a specific restauration system, directly managed or granted a catering operator, homemade or coming from a central kitchen, or even resorting to the agri-food industry that provides ready-made solutions. According to the data emerging from our survey, we've evaluated the adequacy of the "healthy catering card" (HCC) being developed by the agri-food group DAVIGEL for other pathologies or specific nutritional situations to the needs of cancer care units. This model of supply, based on products made by the agri-food industry offers highly standardized dishes, frozen and ready-made, which is likely to reduce the day-to-day dietary variability in our study and secures our experimental protocol. The palatability tests that we have conducted with the panel of patients may allow completing our innovative culinary approach.

\section{Method}

The study of the food supply in a hospital took place in 2014 following two phases. Firstly a specific survey was conducted in Beauvais hospital center (BHC), in which the restoration works in direct management. This monocentric study has been limited to outpatients and week in-patients departments. Indeed, the radiotherapy department offers no catering service. The food supply of palliative care service is very specific since it is tailored to the needs of the patient at the end of life, so was not included in the study. The survey includes major patients treated with chemotherapy for 3 to 6 months. Among them, 17\% also received radiation therapy. The sample comprised $44 \%$ of retirees, consists of $56 \%$ of women and $44 \%$ of men between the ages of 45 and 60 . Men have been mainly treated for colorectal cancer or lung cancer (Table 1). Women have been predominantly treated for breast cancer (Table 1). A total of 41 patients completed the questionnaire involving a series of closed questions. The interview was conducted by a single investigator to advise the patient if necessary and to ensure the global objectivity. The questionnaire focused on disorders experienced since the beginning of the treatment and collection of meals at home and at the hospital. The time frame of all 107 questions addresses the food intake of one day (i.e. on a "given day"). The questionnaire includes items on the reason for the qualitative and quantitative changes, the preferences of products (nutritional formulations, textures, marks, signs of quality, talking about representations of the food products), the positive and negative connection with experienced symptoms since the implementation of treatments. Patients were asked about their level of knowledge about the dietary recommendations they have received during their course of care and their sources of information. All data was treated anonymously. Data analysis was performed using SPHINX software, then reviewed and summarized by the staff including an expert in therapeutic education, an expert in sensory analysis and a reference nutritionist specializing in oncology. In a second step, we have worked in a sensory analysis laboratory with a group of patients followed in the same hospital and enrolled in the NEODIA translational program since 4 full years. Briefly, this NEODIA trained panel of 8 patients contributing to the present study (42 - 63 years old) was composed of women volunteers regularly entailed by tests of tasting in room of sensory analysis, attends culi-

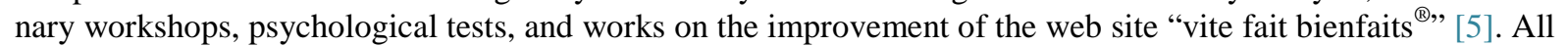
participants have something in common which brings them together, i.e. learning to live with cancer on a day-to-day basis. They are working monthly since 2012 with our research staff. Eligible criteria to participate in the panelin 2012 were: usual cooking practices before their illness, presence of major side effects to investigate, capability to determine taste changes. The women have reported in the initial NEODIA study questionnaire [5] that they had in place specific solutions to alleviate their problems. Developing this expertize, they was able to advise the NEODIA research staff.

In the present study, the 8 cancer bearing women could all participate in 6 working sessions without problems and supervised by our staff. 


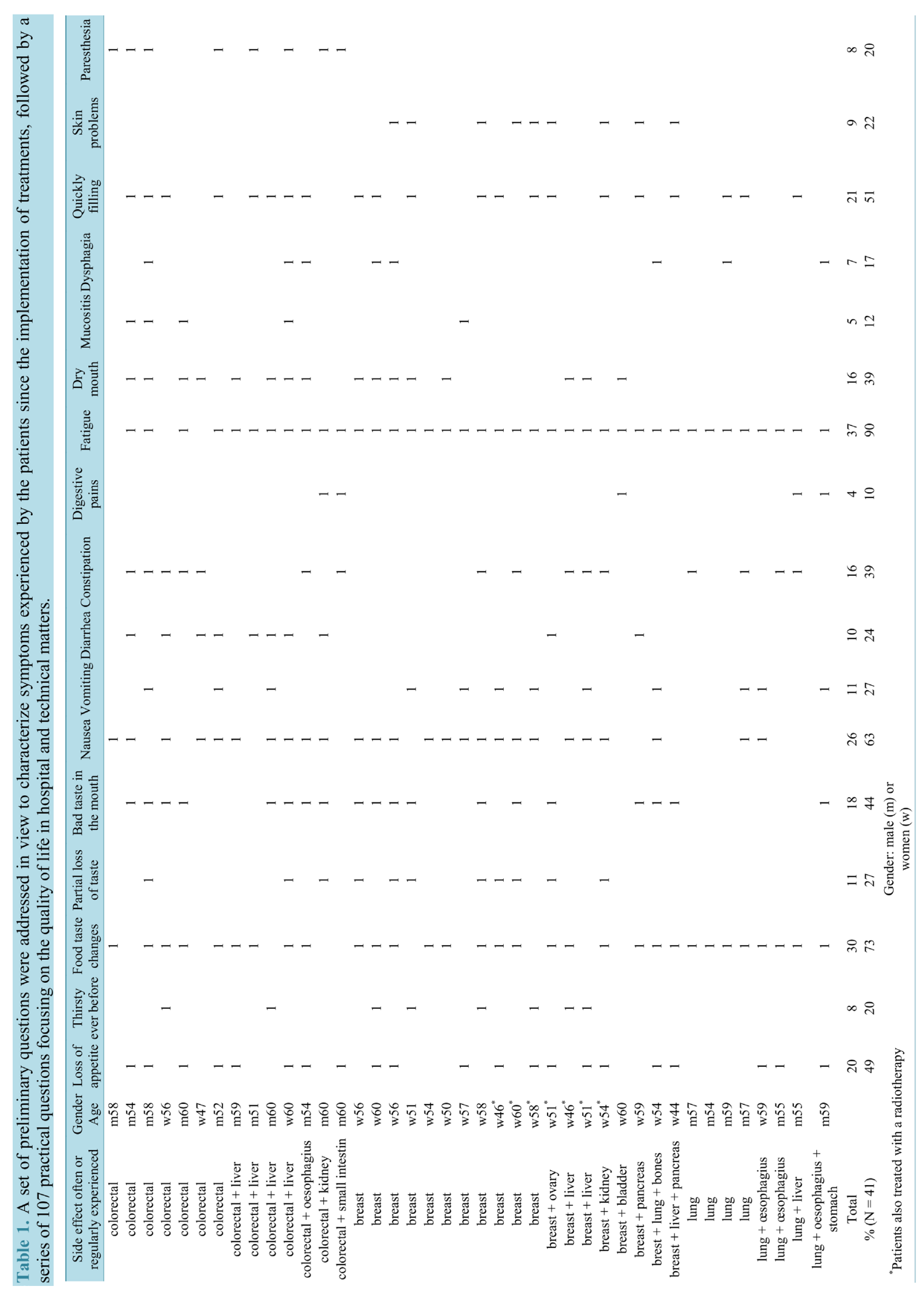


First the ready-made frozen meals of the "Healthy Catering Card" offer (HCC) provide by DAVIGEL are conceptually analyzed on the basis of their ingredients quality and quantity. Then dish were tasted by the panel in the sensory room. To do this, the tempering of frozen sealed trays was performed at $4^{\circ} \mathrm{C}$ for 15 hours and delivery in temperature at 600 watts microwave oven for 3 to 4 minutes depending on the dish size (according to the manufacturer's specifications). The patients themselves remove the tray seal. The database was filled according to a grid of analysis that incorporates the dietary recommendations of the SFNEP [1] and all of the culinary and sensory teachings of the global NEODIA survey [5]. The criteria include smell, visual, taste, the sensations in the mouth, ease of chewing, ease of swallowing. Patients should individually justify the approval or rejection of each criterion. The test did not include quantifying the ingested portion. A dish is "validated" by the panel if it obtains at least 75\% approval per criterion (6 testers on 8). One of the 8 criteria below this threshold suffices to disregard a dish. Thus, in this case patients and researchers found a consensus to provide advice to improve the formulation of the product.

\section{Results and Discussion}

\subsection{Guidelines Driven by the Questionnaire to Patients}

The primary NEODIA survey enrolling 197 people has explained the different determinants that are changing the feeding behavior of patients at home. The present study in 41 patients followed in a cancer care unit was designed to show the impact of both the environmental conditions and the technical constraints of the catering service in hospital on the global quality of life. It is why we have first questioned patients to make sure that they currently experienced side effects since the implementation of treatments, correlating with the global NEODIA data. Considering our pragmatic approach, the individual clinical picture and treatment protocol was not considered in our analysis because the main objective of this questionnaire was to highlight the presence or not of the side effects. Thus, we observed specific side effect closely related to the health conditions of patients with different cancer and treatment (thirsty ever before the treatment, partial loss of taste, vomiting, diarrhea, digestive pain, mucositis, dysphagia, skin problems, paresthesia) (Table 1). By contrast, interestingly, patients have other side effects in common which brings them together. After the two first treatment sessions they often or regularly experienced fatigue (90\%), nausea (63\%), a change in the taste of foods (73\%), loss of appetite (49\%), bad taste in mouth (44\%), dryness of the oral mucosa $(41 \%)$ or constipation (40\%). They also have the sensation to be filled quickly (51\%).

The majority of patients are aware that food have effects on the body, $68 \%$ thought that certain foods are to be promoted or conversely to be avoided depending on their personal situation.

Approximately 66\% patients believed they have received sufficient and satisfactory lifestyle and dietary recommendations, provided by dietitians of the BHC oncology departments. It is worth noting that our survey took place in 2014, and that respondents do not have benefited from the NEODIA culinary education program implemented to this hospital in May 2015.

In BHC oncology departments, the average length of stay (ALS) is 3 days per month for weekly inpatients and 2.5 days per month for outpatients. Today, catering in this hospital operates in direct management. Meals are composed with a starter (usually cold), a hot main course (three choices) and a dessert (yogurt, applesauce). Three meals a day are available for inpatients including 3 choices for the main dishes. For outpatients, lunch offers two choice main dishes. Snacks include hot or cold drinks and a sweet dry cookie.

Our study shows that dishes are considered globally appetizing for $68 \%$ of the peoples. The main course covers food preferences of $78 \%$ of patients.

The flavor of the dishes is undoubtedly the criteria deemed most important for $90 \%$ of the surveyed patients. The gustatory sense is in fact the most altered by treatment, with patients affected by the decrease of taste, deviant flavors and food changes, according to the global NEODIA study [5]. This explains this special interest for flavor management. In the present study, dishes taste blandly (43.9\%) to insipid (12.2\%). Some dishes and broth exacerbated the bad taste in the mouth due to treatments. Only $37 \%$ of eaters say that any offer suits them taste. In fact, patients turn away mainly from metallic flavor for $37 \%$ of them, also from the bitter taste (17\%), or salt (12\%). These people are those who always say they have a bad taste in the mouth. As a reminder, the global NEODIA study [5] shows that the Umani taste is also a brake, like salt, although this flavor enhancer is not used in the collective kitchen. It should be noted that among the $63 \%$ of people saying search specific flavors, $29 \%$ are more attracted by sweets and $19.5 \%$ by intense but not necessarily salty flavors.

Patients also bear great interest to odors, particularly those generated by hot dishes. According to $73 \%$ of the 
patients this item is a priority to be managed in order to limit nausea and vomiting. The appetizers and desserts frequently served cold do not pose any problem. Concerning warm dish, $89.7 \%$ of respondents prefer open the serving cover facing them, waiting a lot for cooling before. Patients are not more in discomfort by the ambient smells of the hospital than by those at the home. It is worth noting that $14 \%$ of them appreciate floral fragrances in living spaces.

A central remark of patients concerns the quantities of food offered. Since the establishment of the treatment the volume of meals taken at home is less in $57 \%$ of patients $(\mathrm{N}=41)$. This confirms the results of the NEODIA study $(\mathrm{N}=197)$ which shows that $58 \%$ of the patients reported having much less $(6.6 \%)$ or less of appetite (26.4\%), or an irregular appetite (25\%). Nearly half of patients from the present study $(49 \%, N=41)$ say they have less appetite into the hospital than at home. Some $65 \%$ of them believe the cold atmosphere of the hospital accentuates the phenomenon of food refusal, but not only (several possible answers given). They also don't like the menu (25\% of respondents), they eat alone or with people they don't know (20\%), the odors of any types disturb them (10\%), outpatients wish to leave as soon as possible (10\%) others (5\%) not knowing why.

Patients $(34 \%, N=41)$ consider the mealtray gets too crowded. Dry biscuits blister-pack, which constitutes the dry product of the snack with a drink, is arranged on the lunch tray. Patients think that this increases the risk of refusal. Moreover, patients have problem with the main dish, because $66 \%$ of them saw it as too large. Then, $90 \%$ do not eat all of their food. It is interesting to note that only $14 \%$ of patients in the study continue to perceive as a pleasant meal in the hospital, compared to $29.3 \%$ in their House. If for them "a good meal" remains characterized mainly as a friendly family time, or even the prospect of a good dish, it is also now identified by $17 \%$ of them as a meal that they primarily reach to finish despite the side effects. Could only one full meal in lieu of the entree plus the main course be sufficient? The people who answer this questionnaire, French by birth or integration, are accustomed to French food practices, whereas a three-course meal. This explains why the opinions are very divided, with $51.2 \%$ to $48.8 \%$ against this idea.

The question on the frequency of meals and snacks proposed at the BHC has collected $83 \%$ satisfaction. Clearly, despite searching for smaller quantities of food, inpatients included in week therapeutic programs prefer to keep three meals daily. We must say that the arrival of the meal still triggers hunger for $51 \%$ of the patients, which is important to preserve. Eating at the request is not a claim for $75.5 \%$ of patients. On the other hand, they emphasize that the food turnover is important, so that people coming regularly each month can have a good variety on their return.

The temperature of the dishes is a criterion considered as essential to take into account for $71.5 \%$ of patients, depending on different situations to which they are adapted. Especially prone to nausea or mouth inflammation people eat foods at room temperature or cold, participating to numb the mouth. Patients who have diarrhea avoid ingestion of cold food. Those with paresthesia also avoid very cold dishes to not trigger sensation of tingling located into the digestive tract. Taste and smell impairment leads to avoiding extreme temperatures.

It's also worth noting that $70 \%$ of patients are bearing great interest to the presentation of the dish and the lunch tray since the establishment of their treatment. Surprisingly, in our study only $2 \%$ of patients wanted to lunch in a plate close to the design used at home. They prefer (63\% of them) to separate the sauced source of protein (meat/fish) and the side dish, if not starchy food or even vegetables will absorb the sauce which is not always appreciated depending on the therapeutic adverse effects. Presentation of the dishes on plastic trays doesn't bother for $90.2 \%$ of the interviewees, as long as it is compartmentalized.

Patients are concerned about the color of the food. Thus they are 59\% preferring a dish in which the natural color of ingredients is preserved by the cooking techniques. They appreciate the presence of some colorful ingredients, such as aromatic herbs or vegetables incorporated as topping in starches. In their opinion this is whetting the appetite.

Concerning the textures of food, our survey indicates that $63 \%$ of patients who eat in the hospital are choosing the juiciest and tender foods cut into small pieces. They prefer a creamy sauce spooned on a meat or a fish piece rather than a juice, in order to ease chewing, to avoid fatigue, as well as oral canker sores, dry mouth, but also stimulation of inflammation such as gingivitis.

\subsection{Sensory Analysis of Standardized Frozen Meals Ready-Made (Laboratory Study)}

The commercial offer "healthy catering card" provided by DAVIGEL answers to the needs of people hospitalized which follow specific nutritional recommendations. Recipes are adapted to diabetic diet, also for people suffering from cardiovascular diseases, for the impaired renal function with dialysis, for people suffering of 
malnutrition, for dishes without large residue (digestive savings), or even for low salt meals. A same dish may be suitable for different types of hospitalized people.

The offer consists of three types of dishes. Dishes " 3 components" are subdivided in 2 compartments plastic tray with a transparent cover's shape. One contains cooked proteins $90 \mathrm{~g}$ to $100 \mathrm{~g}$ for an adult portion spooned with $50 \mathrm{~g}$ sauce. The other compartment presented $100 \mathrm{~g}$ of accompanying vegetables. The tray weighs 300 $350 \mathrm{~g}$ in total, according to the recipe. Dishes "complete meal" are presented in a single uncompartementalized trayas a gratin, Parmentier, pasta, risotto, backed pancakes or pies, containing $70 \mathrm{~g}$ of proteins. Dishes "constant” are single products such as cooked starches (150 g), vegetables (220 g), or cooked animal proteins (90 to $140 \mathrm{~g}$ meat or fish) also presented in a single tray.

During our laboratory investigations, the compartmentalized white plastic tray was appreciated by all the 8 patients of the NEODIA translational research panel, because the cover's shape system keeps smells inside the tray. This observation correlates with the results of our survey including 41 people (see before). The panel highlights a guarantee of safety during the service. Unanimously, testers want to remove the cover's shape themselves, just as they would normally at hospital.

Table 1 and Table 2 summarize the main comments received by the panel of patients during palatability tests.

The meats (red meat or chicken) are appreciated when they are sliced into pieces or chopped to obtain meltin-the-mouth texture (Table 2). This is allowed by cooking under vacuum, as well as steam cooking (under pressure or not), or delta $\mathrm{T}$ cooking used in industrial processes advantageously. Chewing and swallowing are therefore facilitated to provide the same pleasure obtained when fish or eggs are consumed, particularly in patients presenting mouth and back of the throat inflammation. Conversely, the meat too dry, oily or even roasted are denied (Table 3). The first are difficult to return in a dry mouth, seconds are long to digest and inducers of gastric reflux, the latter are sources of nausea. Without glutamate or poor salt sauces are accepted (Table 2). Specific herbs and spices leave in mouth freshness. Thick sauces are preferred to meat broths (Table 3). Salted sweet associations borrowed from the traditions of North Africa appeal to the greatest number. Vegetables done right, conveniently mixed with starch (rice, pasta, quinoa, semolina), are source of pleasure due to their tenderness (Table 2). Cold vegetables refresh a mouth sored by inflammation. Conversely, as shown in Table 3, fried in fat (butter or oil) vegetables turn oily and produce a nauseating odor linked to the presence of the Maillard brown products. Firm or crisp vegetables, cereals or starchy undercooked foods will cause a refusal for various reasons (wrong swallowing, painful teeth and gums, canker sores). Iron-rich legumes may cause the same aversion as red meat (Table 3) by amplifying this metallic taste in the mouth starting from the beginning of some treatments. Adding milk derivatives in purees (butter, cream) and in vegetables sauces enhance the energy profile of the dish to increase lubricity for chewing without effort. In the same spirit, the incorporation of meat tapered into a risotto or a fish quenelle will avoid wrong swallowing.

Altogether the study treated 79 culinary solutions, analyzing 52 dishes " 3 components" and 27 dishes "complete meal" or "constant". Finally, 57 solutions are accepted by patients. Focusing on families of ingredients proposed, only 6 dishes of red meat on 16 were appreciated, as well as 5 of 8 pork specialties (including ham). Inversely, 17 out of 20 poultry dishes, 7 out of 8 egg recipes, 13 out of 16 dishes of fish, and 9 out of 11 of vegetables/starchy foods were selected.

Table 2. Reference table of inclusion criteria brought by the panel of patients NEODIA $(\mathrm{N}=8)$ during the tests of palatability of the ready-made meals "Healthy Catering Card" (HCC).

\begin{tabular}{|c|c|c|}
\hline Compound family & Inclusion criteria & Rational \\
\hline Meat, fish, egg & $\begin{array}{l}\text { Small pieces } \\
\text { Flexible and melt texture } \\
\text { Textured meat, shepherd's pie } \\
\text { Meat, and fish loaf } \\
\text { Egg products }\end{array}$ & $\begin{array}{l}\text { Chewing and swallowing ability improved } \\
\text { Chewing and swallowing ability improved } \\
\text { Freshness and fluid in mouth when served cold or warm }\end{array}$ \\
\hline Sauce & $\begin{array}{l}\text { Low level chloride sodium } \\
\text { No glutamate sodium } \\
\text { Oriental flavoured spices } \\
\text { Sweeten-salted dishes } \\
\text { Herbs and soft spices }\end{array}$ & $\begin{array}{l}\text { Avoid flavour enhancer } \\
\text { Avoid nausea and vomiting } \\
\text { Subtle tastes } \\
\text { Swetty subtile tastes, optimum sweet/sour balance } \\
\text { Freshness in mouth }\end{array}$ \\
\hline $\begin{array}{l}\text { Vegetables starchy } \\
\text { food }\end{array}$ & $\begin{array}{l}\text { Zucchinis, carrots, potatoses, cucumber... } \\
\text { Starch items and vegetables mix } \\
\text { Puree with cream, cheese, eggs }\end{array}$ & $\begin{array}{l}\text { Moist and smooth textures/Freshness in mouth when served cold } \\
\text { Chewing and swallowing ability improved/visual stimulation } \\
\text { Nutritional enrichment }\end{array}$ \\
\hline
\end{tabular}


Table 3. Reference table of exclusion criteria brought by the panel of patients NEODIA $(\mathrm{N}=8)$ during the tests of palatability of the ready-made meals "Healthy Catering Card” (HCC).

\begin{tabular}{lll}
\hline Compound family & Exclusion criteria & Rational \\
& Red meat, blood sausage & Sweet metallic taste \\
& Sausage & Fatty, strong-smelling \\
& Pork meat & Dry, strong-smelling \\
Meat, fish, egg & Wings & Strong smelling and elastic grilled skin \\
& Chicken filet or chicken leg & Anatomical piece of meat too big \\
& Filet, cutlet & Strong-smelling \\
& or breaded dried fish & \\
\hline \multirow{5}{*}{ Sauce } & Sodium Mono Glutamate & Umami taste \\
& High level chloride sodium & Avoid flavour enhancer \\
& Too small quantity sauce & Dry pieces of meat \\
& Meat juice and broth & Umami taste, Maillard-reaction bitterness \\
\hline \multirow{2}{*}{ Vegetables \& starchy } & Beans & Bloating and flatulence \\
food & Fried vegetables & Sweet metallic taste and demineralizing phytic acid \\
& Cruciferous veg (cabbage) & Oily/fatty taste \\
& Risotto & Sulfur odour \\
\hline
\end{tabular}

\section{Conclusions}

It is now well established and recognized by the scientific and clinical community that an optimal nutritional status in cancer patients is crucial on the prognosis of healing. Unfortunately, the symptoms of the disease as well as the side effects of treatments impair patients in their daily food intake, directly or indirectly. The NEODIA survey enrolling 197 people has explained the different determinants that are changing the feeding behavior of patients at home. The present study in 41 patients followed in a cancer care unit has allowed showing that environmental conditions and the technical constraints of the catering service in hospital have worsened the situation. The responses of the patients regardless of the type of cancer are ways for improving quality of dishes and their presentation in hospital, to meet the metabolic requirements. On the basis of palatability using laboratory tests, the study of a wide range of dishes by a panel of trained patients refines the information about food preferences specific to oncology. Beyond the nutritional value of meals studied, already referenced in hospital catering, olfacto-gustatory criteria used by cancer patients guide now the acceptance of dishes based on the side effects felt. In our study we observe that dishes of chicken, egg products, but also fish is approved. The red meat and pork dishes (excluding ham) are neglected. Discussions with the dieticians of 160 hospitals in our exchange program clearly confirm the interest for the chicken and the egg products. The place of the fish is rather controversial, depending on the quality of the raw product. Fish is a fragile product and special attention should be taken to avoid ammonia odor. In our study tested fish is from a premium quality supply chain, which is the expertise of the provider DAVIGEL. This is not surprising to see this type of meal moving up in the rankings in our study. Red meat will find their salvation only by modifying existing recipes. The pork meat will remain the most difficult to work. But do we really need a complete supply of animal protein for patients? Range "undernutrition 3-component" of the HCC appears as a reference. Indeed, they have a total energy load greater than 450 kcal per serving, provided by at least $22 \%$ protein. They meet the total protein-energy needs estimated to 25 - 30 $\mathrm{kcal} \cdot \mathrm{kg}^{-1} / \mathrm{d}$ in perioperative situations and to $30-35 \mathrm{kcal} \cdot \mathrm{kg}^{-1} / \mathrm{d}$ in medical oncology [1]. This corresponds to a protein intake of 1.2 to $1.5 \mathrm{~g} \cdot \mathrm{kg}^{-1} / \mathrm{d}$.

We believe that future culinary research should concentrate on simple dishes to enrich energy if they are not enough. The use of herbs and specific spices will be a real innovation in catering dedicated for care units in view to mitigate some side effects. The website "right cooking for a right life" ("Vite fait bienfaits") from our NEODIA program goes in this direction. Furthermore, these aromatic natural foods are useful to reduce salt. The threshold of $120 \mathrm{mg} / 100 \mathrm{~g}$ has to be recommended. This maximum level is use in HCC dishes dedicated for diabetics (to reduce hypertension), in dishes suitable for renal failure (to prevent weight gain during dialysis protocol), or in the case of cardiovascular diseases (to improve blood pressure control).

Catering in oncology units addresses a particular problem, compared to the nutritional support related to other diseases. Food choices of cancer patients are very likely to change after the appearance of side effects by the treatments particularly olfactory and gustatory deviations. Catering operators have to choose from two diametr- 
ically opposed postures. Simplistically, "ham and mashed potatoes" (pork, as well as chicken or turkey meat) given in all situations managed in oncology care units would certainly unanimous in any point of view "easy to prepare and easy to eat”. But the patient, who was supported in hospital day care lunching only on-site, must return in fact frequently in the care unit, when he is not hospitalized for a longer stay. The feeding program is complicated so much. In the present study, a large number of meals from the ready-made HCC are particularly suitable for cancer patients. This offer is broad enough not only for hospital day care but could be of interest for week hospitalization, or why not long-term admissions.

Our study highlights that meals currently eaten at hospital in oncology care unit are perceived as a disruption in the nutritional care program, for a third of surveyed patients. Yet the Beauvais Hospital is already very attentive on this point. The idea of a more interventionist posture in hospital catering caught on: "food is a supportive care and cooking is like a prescription". Suggesting that diet allows directly treating the disease is out of the question. Alleviation or arrest of symptoms linked to treatments and therefore improving the quality of life is reality using regular foods via nutritional counseling [8] [16].

A healthy catering concept adapted to the cancer disease has earned a place in the current therapeutic patterns. This issue has to be integrated by all professionals involved in oncology care management including catering operators as an educational interdisciplinary value during the stay of the patients in hospital. This initiative should come in additions to lifestyle and dietary advices given in oncology care units or educational culinary workshops as existing currently in more and more hospital in France.

Intensive individualized nutritional counseling requires nutrition professionals with specific experience in oncology embodied by dieticians.

The French National Cancer Institute (INCA) enumerates 944 care facilities in France with appropriate cancer care authorization. Each medical institution possesses a specific restauration system, directly managed or granted a catering operator, homemade or coming from a central kitchen, or even resorting to the agri-food industry that provides ready-made solutions. Depending on the management that the cancer care units chose (day-care, or week-care as well as long-term care in surgical and medical oncology) and related techno-economic flexibility, remarks of cancer patients may be considered as new elements to adapt specifications as a part of the continuous improvement dedicated to the holistic care management in oncology.

In France, the "cancer plan" open in 2014 emphasizes the need to "preserve the continuity and the quality of life, by offering comprehensive support of the person during and after the disease, taking into account all the needs". The multiplication of pragmatic field observations such as those conducted in the NEODIA program is useful to decision makers wanting to manage continuity during the transition from hospital to homecare and vice versa.

\section{Acknowledgements}

We would like to particularly thank the patient's panel of the NEODIA translational research program.

We also wanted to associate the different staffs of the Beauvais Hospital which have contributed to this work.

\section{Statement of Interest}

The NEODIA program (2010-2016) was supported by a grant from the regional health agency of Hauts de France (ARS), the French National Program of Diet (PNA), the French league against cancer (departmental committee of Oise) and the regional council of Hauts de France. DAVIGEL Company provides ready to eat frozen meals as well as financial support to organize workshops in 160 cancer care units in France.

The authors state no conflict of interest linked to this article.

\section{References}

[1] Hébutern, X. (2015) Nutrition and Cancer: Why Take Care of before 5\% Weight Loss? Nutrition Clinique et Métabolisme, 29, 126-131.

[2] Muscaritoli, M., Bossola, M., Aversa, Z., et al. (2006) Prevention and Treatment of Cancer Cachexia: New Insight into an Old Problem. European Journal of Cancer, 24, 31-41. http://dx.doi.org/10.1016/j.ejca.2005.07.026

[3] (2008) Multidisciplinary Clinical Guide to Nutrition Management of Cancer Patients. Consensus. Clinical \& Translational Oncology, Extraordinary, 2, 10.

[4] Laviano, A., Meguid, M.M., Inui, A., et al. (2005) Therapy Insight: Cancer-Cachexia Syndrome When All You Can 
Eat Is Yourself. Nature Reviews Clinical Oncology, 2, 158-165. http://dx.doi.org/10.1038/ncponc0112

[5] Pouillart, P., Bendjaballah, S., Laroche, C., Tiravy, A., Gidoin, E., Chesnay, P., Foissy, C., Toussaint, E., Pouillart, Compère, O. and Dutel, J.L. (2015) Cooking during a Cancer: What Teaches Us Patients of the Translational Group of Research NEODIA. Nutrition \& Endocrinology, 13, 127-135.

[6] Van Cutsem, E. and Arends, J. (2005) The Causes and Consequences of Cancer-Associated Malnutrition. European Journal of Oncology Nursing, 9, S51-S63. http://dx.doi.org/10.1016/j.ejon.2005.09.007

[7] Senesse, P., Assenat, E., Schneider, S.M., et al. (2008) Nutritional Support during Curative Treatment of Patients with Gastrointestinal (GI) Cancer: Who Could Benefit? Cancer Treatments Reviews, 34, 568-575. http://dx.doi.org/10.1016/j.ctrv.2008.03.003

[8] Ravasco, P. (2005) Aspects of Taste and Compliance in Patients with Cancer. European Journal of Oncology Nursing, 9, S84-S91. http://dx.doi.org/10.1016/j.ejon.2005.09.003

[9] Muscaritoli, M. (2004) Therapy of Muscle Wasting in Cancer: What Is the Future? Current Opinion in Clinical Nutrition and Metabolic Care, 7, 459-466. http://dx.doi.org/10.1097/01.mco.0000134366.07148.2e

[10] Laurent, A., Nicco, C., Chéreau, C., et al. (2005) Controlling Tumor Growth by Modulating Endogenous Production of Reactive Oxygen Species. Cancer Research, 65, 948-956.

[11] Alexandre, J., Nicco, C., Chéreau, C., et al. (2006) Improvement of the Therapeutic Index of Anti-Cancer Drugs by the SOD-Mimic Mangofodipir. Journal of the National Cancer Institute, 98, 236-244. http://dx.doi.org/10.1093/jnci/djj049

[12] Mason, J.B. (2008) Gastrointestinal Cancer: Nutritional Support. In: Kelsen, D.Dp., Daly, J.M., Kern, E., Levin, B. and Van Cutsem, E., Eds., Principles and Practices of Gastrointestinal Oncology, Lippincott Williams and Wilkins, 87-99.

[13] Andreyev, H.J., Norman, A.R., Oates, J. and Cunningham, D. (1998) Why Do Patients with Weight Loss Have a Worse Outcome When Undergoing Chemotherapy for Gastrointestinal Malignancies? European Journal of Cancer, 34, 503-509. http://dx.doi.org/10.1016/S0959-8049(97)10090-9

[14] Ross, P.J., Ashley, S., Norton, A., et al. (2004) Do Patients with Weight Loss Have a Worse Outcome When Undergoing Chemotherapy for Lung Cancers? British Journal of Cancer, 90, 1905-1911. http://dx.doi.org/10.1038/sj.bjc.6601781

[15] Cessot, A., Agostini, J., Camps, S., et al. (2010) Relationship between Performance Status, Nutritional Status and Chemotherapy Dose-Intensity in Patients with Solid Tumors. European Society for Medical Oncology, S3310.

[16] Ravasco, P. (2015) Nutritional Approaches in Cancer: Relevance of Individualized Counseling and Supplementation. Nutrition, 31, 603-604. http://dx.doi.org/10.1016/j.nut.2014.12.001 